University of Nebraska - Lincoln

DigitalCommons@University of Nebraska - Lincoln

U.S. Environmental Protection Agency Papers

U.S. Environmental Protection Agency

2009

Interactions Between Biological and Abiotic Pathways in the Reduction of Chlorinated Solvents

Richard A. Brown

ERM, Inc.

James G. Mueller

Adventus Americas Inc.

Alan G. Seech

Adventus Americas Inc.

James K. Henderson

DuPont Corporate Remediation Group

John T. Wilson

U.S. Environmental Protection Agency

Follow this and additional works at: https://digitalcommons.unl.edu/usepapapers

Brown, Richard A.; Mueller, James G.; Seech, Alan G.; Henderson, James K.; and Wilson, John T., "Interactions Between Biological and Abiotic Pathways in the Reduction of Chlorinated Solvents" (2009). U.S. Environmental Protection Agency Papers. 116.

https://digitalcommons.unl.edu/usepapapers/116

This Article is brought to you for free and open access by the U.S. Environmental Protection Agency at DigitalCommons@University of Nebraska - Lincoln. It has been accepted for inclusion in U.S. Environmental Protection Agency Papers by an authorized administrator of DigitalCommons@University of Nebraska - Lincoln. 


\section{Interactions Between Biological and Abiotic Pathways in the Reduction of Chlorinated Solvents}

Richard A. Brown

James G. Mueller

Alan G. Seech

James K. Henderson

While biologically mediated reductive dechlorination continues to be a significant focus of chlorinated solvent remediation, there has been an increased interest in abiotic reductive processes for the remediation of chlorinated solvents. In situ chemical reduction (ISCR) uses zero-valent iron (ZVI)-based technologies, such as nanoscale iron and bimetallic ZVI, as well as naturally occurring John T. Wilson reduced minerals incorporating dual-valent iron (DVI), such as magnetite, green rust, and iron sulfides that are capable of dechlorinating solvents. A more recent area of development in ISCR has been in combining biological and abiotic processes.

There are several ways in which biological and abiotic processes can be combined. First, the interaction between the two may be "causative." For example, the Air Force Center for Engineering and the Environment's biogeochemical reductive dechlorination (BiRD) technology combines a mulch barrier with hematite and gypsum to create an iron-sulfide-based reducing zone. Biodegradation under sulfate-reducing conditions produces sulfide that combines with the hematite to form iron sulfides. As such, the BiRD technology is "causative"; the biological processes create reducing minerals. The biological generation of other reducing minerals such as magnetite, siderite, and green rust is feasible and is, with magnetite, observed in nature at some petroleum sites. A second type of interaction between abiotic and biotic processes is "synergistic." For example, biological processes can enhance the activity of reduced metals/minerals. This is the basis of the $E H C^{\circledR}$ ISCR technologies, which combine ZVI with a (slowly) degradable carbon substrate. This combination rapidly creates buffered, strongly reducing conditions, which result in more complete solvent degradation (i.e., direct mineralization). The extent and level of reducing activity commonly observed are much greater when both the carbon substrate and the ZVI are present. When the carbon substrate is expended, the reducing activity due to ZVI alone is much less.

The understanding of biogeochemical processes and their impact on abiotic processes is still developing. As that understanding develops, new and improved methods will be created to enhance volatile organic compound destruction. (C) 2009 Wiley Periodicals, Inc.

\section{INTRODUCTION}

The investigation of natural attenuation processes at contaminated sites has commonly focused on biological degradation of compounds of concern. Recently, it has become increasingly apparent that abiotic mechanisms also play an important role in contaminant degradation. Historically, where evidence of biological degradation was lacking, it would 


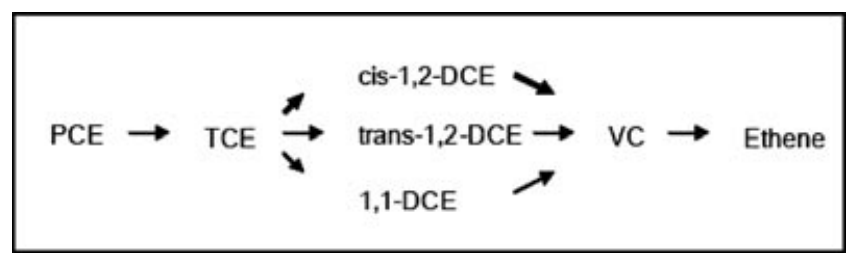

Exhibit 1. Sequential reductive dechlorination of PCE

commonly have been assumed that nondestructive processes, such as adsorption, dispersion, and volatilization, were responsible for declining concentration trends. Recent research, however, has shown that abiotic reductive processes often represent an important remedial pathway at these sites and account for significant declines in contaminant levels. There are two reductive processes used to treat chlorinated solvents (CVOCs): biologically mediated reductive dechlorination (reductive dechlorination), and in situ chemical reduction (ISCR). While both ultimately involve the transfer of electrons to the chlorinated solvent, resulting in dechlorination, the pathways and the mechanisms are quite different.

\section{Reductive Dechlorination}

Reductive dechlorination is a distinct metabolic pathway wherein halo-respiring bacteria use the $\mathrm{CVOC}$ as an electron acceptor. The electron donor is typically a carbon substrate or molecular hydrogen (produced by the fermentation of a carbon substrate). The dechlorination is a sequential hydrogenolysis wherein chlorines are replaced by a hydrogen ion $\left(\mathrm{H}^{+}\right)$. Both the hydrogen-ion addition and the chlorine removal require an electron. The reduction, therefore, involves two sequential electron transfers that are mediated by halo-respiring bacteria.

Exhibit 1 depicts the complete reductive pathway for tetrachloroethene (PCE). The degradation sequence is tetrachloroethene $\rightarrow$ trichloroethene $\rightarrow$ dichloroethene $\rightarrow$ vinyl chloride $\rightarrow$ ethene. Trichloroethene (TCE) can degrade into three different isomers of dichloroethene (DCE) — cis, trans, and 1,1-; however, cis-1,2-DCE is the dominant product.

\section{ISCR}

ISCR also involves two electron transfers. The electrons are supplied by a reduced metal, such as zero-valent iron (ZVI) or ferrous iron (dual-valent iron, or DVI). Iron-mediated reductive pathways are, in general, different from those that occur with strictly biologically mediated reduction. In particular, the primary reaction products from the reduction of chlorinated ethenes are acetylenes, not ethenes. The primary abiotic reaction pathway is a $\beta$-elimination in which chlorines on adjacent carbon atoms are removed, forming a third $\mathrm{C}-\mathrm{C}$ bond. PCE is reduced to dichloroacetylene through this pathway. Abiotic reduction of the CVOCs can also go through the hydrogenolysis pathway. Hydrogenolysis typically accounts for only 10 percent of the reduction of the parent compound (Arnold, 2000). However, hydrogenolysis reactions may be used to further reduce the chloroacetylenes that are formed. Overall, abiotic reaction pathways are more complex than biologically mediated pathways. 


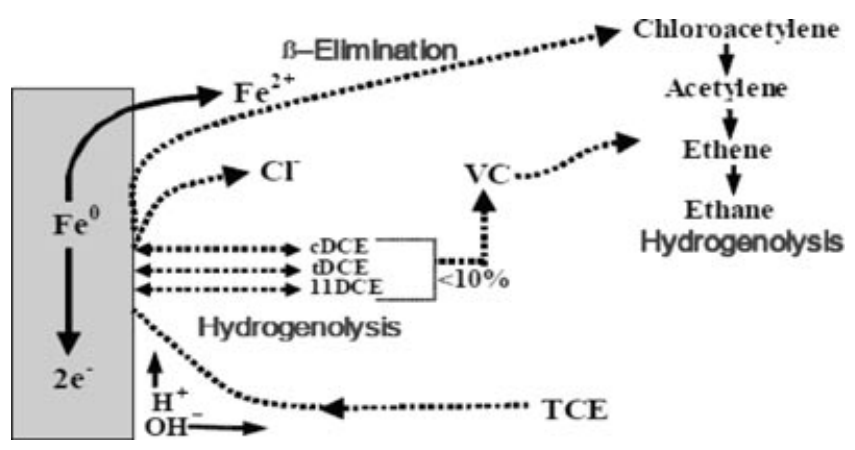

Exhibit 2. Abiotic reduction of TCE by ZVI

Exhibit 2 depicts the abiotic reduction of TCE by ZVI. It involves both $\beta$-elimination and hydrogenolysis. Approximately 90 percent of the TCE goes to chloroacetylene; 10 percent to DCE (primarily cis). The DCE and chloroacetylene are further reduced through hydrogenolysis ending in ethene and ethane. Chloroacetylenes can also hydrolyze to acetic acid:

$$
\mathrm{Cl}-\mathrm{C} \equiv \mathrm{C}-\mathrm{H}+2 \mathrm{H}_{2} \mathrm{O} \rightarrow \mathrm{CH}_{3} \mathrm{CO}_{2} \mathrm{H}+\mathrm{HCl}
$$

Whether hydrolyzed or further reduced, chloroacetylenes are short-lived in groundwater.

\section{Combined Abiotic and Biotic Processes}

Biotic and abiotic reductive pathways are commonly viewed as unrelated. As a result, the development of these two reductive technologies has commonly been separate. Reductive dechlorination has focused on enhancing the microbiology through the use of improved carbon substrates or through bioaugmentation. ISCR has focused on understanding and enhancing the rate and or density of electron transfer through the use of nanoscale ZVI, bimetallic ZVI, or the use of chemical reductants to enhance DVI formation. More recently, however, there has been a growing awareness of and interest in the interaction between biological and abiotic processes.

Current research and development implies that there are two types of biotic-abiotic interactions. One is a causative relationship; the other is a synergistic relationship. In a causative interaction, biological reactions are used to create reducing minerals, such as iron sulfides or reduced-iron oxides like magnetite. In synergistic interactions, one process is used to enhance the reactivity or efficacy of the other. Both types of interactions will be discussed.

\section{CAUSATIVE INTERACTIONS}

The reductive capacity of reduced minerals has been a central theme in ISCR technology. It has focused on the geochemistry of iron minerals. Reduced iron minerals, including iron sulfides, iron oxides, iron carbonates, and mixed oxides (green rust), have been found to be active dechlorinating minerals. Reducing minerals have also been artificially created by the addition of ferrous iron to steel slag and clays. 


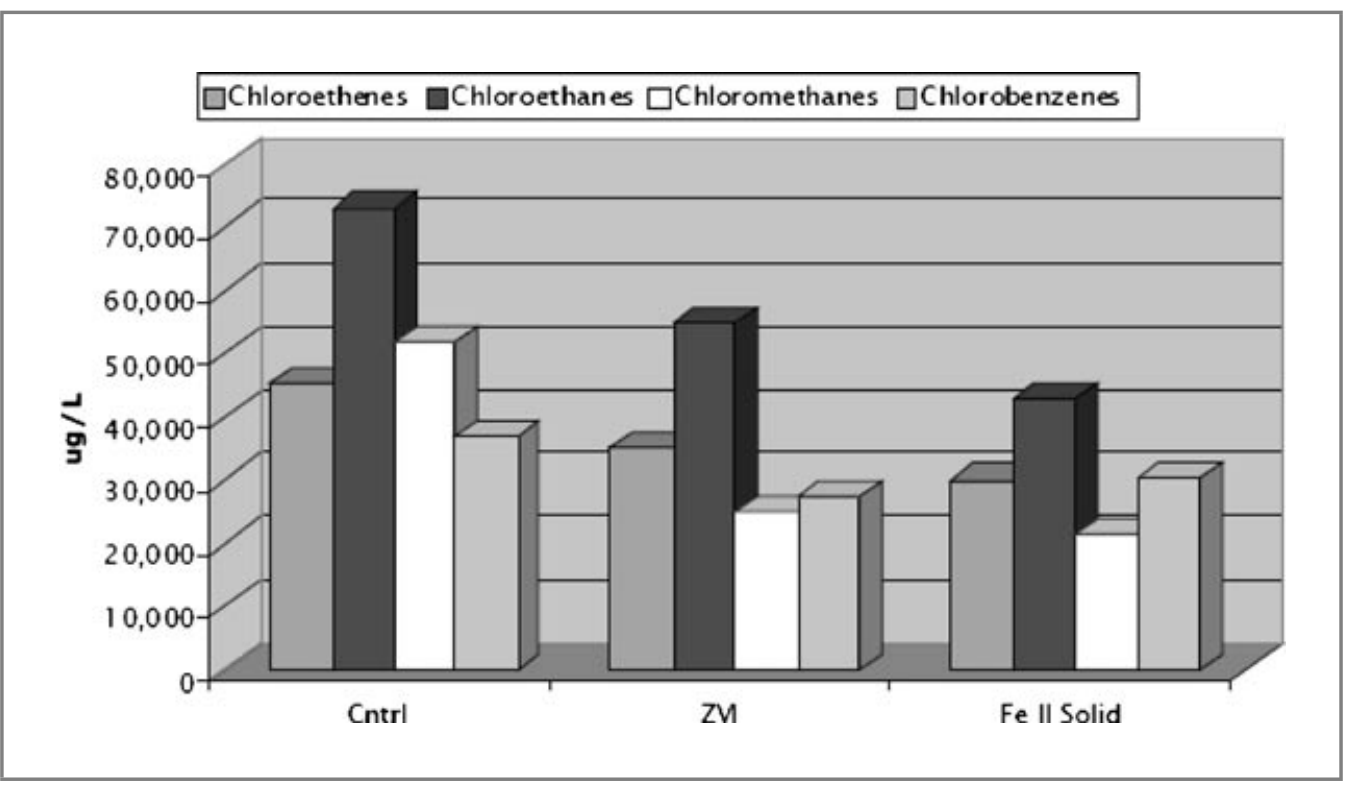

Exhibit 3. Reduction of chlorinated solvents with precipitated ferrous oxide

The abiotic reduction of chlorinated solvents by naturally occurring reduced iron minerals is a major attenuation pathway (Brown et al., 2006; Wilson, 2003). Significant degradation of parent compounds, such as 1,1,1-TCA, PCE, and TCE, is often observed without the accumulation of daughter products, indicating abiotic pathways.

Active reduced minerals have been emplaced through matrix modification, which chemically increases the amount of reduced iron minerals present. There are two methods. First is the injection of chemical reductants to convert existing oxidized-iron minerals to reduced-iron minerals. The injection of sodium dithionite into an iron-rich, oxidized matrix creates a reduced zone, which abiotically reduces TCE (Szecsody et al., 2004). A second method of matrix modification is the direct emplacement of reduced iron. Exhibit 3 shows laboratory data on the relative reactivity of ferrous iron with a mixture of chlorinated compounds including ethenes, ethanes, methanes, and benzenes. Over a 14-day reaction period, precipitated ferrous iron oxide solids (DVI) showed a level of activity equivalent to ZVI (200 mesh). The DVI and ZVI were added in chemically equivalent amounts.

While commonly thought to be unrelated technologies, there is increasing evidence that biotic and abiotic reactions may be interrelated. One area of interaction is the biogenic production of reduced-iron minerals. The biological process "causes" the formation of the reducing mineral. ISCR research and development is broadening from geochemistry to biogeochemistry.

\section{Biogenic Minerals}

Bacteria use carbon to grow and produce energy. The metabolism of carbon requires an electron acceptor. While there are a number of reductive metabolic pathways, two pathways, iron reduction and sulfate reduction, can have a substantial effect on abiotic processes. 
Iron reduction uses ferric iron to metabolize carbon, producing soluble ferrous iron:

$$
2 \mathrm{H}_{2} \mathrm{O}+-\mathrm{CH}_{2}-+6 \mathrm{Fe}^{+3} \rightarrow \mathrm{CO}_{2}+6 \mathrm{Fe}^{+2}+6 \mathrm{H}^{+}
$$

The reduced iron can combine with solid-phase ferric iron to produce reducing minerals such as magnetite or green rust (Chaudhuri, 2001; Moore, 2003):

$$
\mathrm{Fe}^{+2}+\mathrm{Fe}_{2} \mathrm{O}_{3} \text { (hematite) }+\mathrm{H}_{2} \mathrm{O} \rightarrow \mathrm{Fe}_{3} \mathrm{O}_{4} \text { (magnetite) }+2 \mathrm{H}^{+}
$$

Reduced-iron-bearing minerals that form from the precipitation of dissolved iron are capable of mediating abiotic dechlorination reactions. Ferrey et al. (2004) studied a groundwater plume in a magnetite-rich geology that contained both 1,2-cis-DCE and 1,1-DCE. Using aquifer sediment from three different intervals within the impacted plume, they evaluated the degradation rates of the constituents of interest. The first-order rate constant determined in the laboratory for cis-DCE varied from 0.31 to 2.29 per year and, for 1,1-DCE, was 1.37 per year. Autoclaved soil had the same degradation rates as did the ambient soil, indicating that the dechlorinating activity was abiotic.

Sulfate reduction converts sulfate to sulfide. The sulfide then reacts with dissolved- or solid-phase iron (Fe II of Fe III) to produce iron sulfides:

$$
\begin{aligned}
4\left(-\mathrm{CH}_{2}-\right)+3 \mathrm{SO}_{4}^{-2} & \rightarrow 4 \mathrm{CO}_{2}+3 \mathrm{~S}^{-2}+4 \mathrm{H}_{2} \mathrm{O} \\
2 \mathrm{Fe}^{+3}+3 \mathrm{~S}^{-2} & \rightarrow \mathrm{FeS}+\mathrm{FeS}_{2} \\
\mathrm{Fe}^{+2}+\mathrm{S}^{-2} & \rightarrow \mathrm{FeS}
\end{aligned}
$$

The Air Force Center for Engineering and the Environment (AFCEE) has developed a barrier technology that uses sulfate-reducing technology to create a reduced-iron mineral zone. The technology is termed Biogeochemical Reductive Dechlorination (BiRD; Kennedy et al., 2006). To apply this technology, a trench is filled with a mixture of wood mulch, gypsum, and an iron oxide. Iron-reducing and sulfate-reducing conditions are created, resulting in the precipitation of iron sulfides. The iron sulfides create a reduced mineral zone, resulting in the dechlorination of the CVOCs. Iron sulfides formed by biological processes have been found to be more reactive than naturally occurring species, potentially due to greater surface area (AFCEE, 2008).

Exhibit 4 depicts the performance of a BiRD trench. Sulfate levels dropped as the groundwater flowed through the trench and the sulfate was reduced to sulfide, which reacted with the hematite. Exhibit 4 has a photo inset showing the mulch particles coated with black iron sulfide. TCE was subsequently reduced in the trench without the creation of daughter products. Mulch trenches (wood chips only) typically produce significant quantities of daughter products. The lack of daughter products produced in the BiRD trench is a strong indication of an abiotic reductive pathway.

In investigating the behavior of the BiRD technology, Shen and Wilson (2007) evaluated the removal of TCE in a laboratory column that simulated the passive reactive barrier constructed with plant mulch (a BiRD biowall). Groundwater containing 1,000 to $2,000 \mathrm{mg} / \mathrm{L}$ of sulfate flowed through a reactive bed composed of shredded plant mulch and river sand containing iron(III) coatings. Sulfate reduction driven by anaerobic biodegradation of the plant mulch produced as much as $100 \mathrm{mg} / \mathrm{L}$ of sulfide. The sulfide reacted with the iron in the river sand to produce 500 to $2,500 \mathrm{mg} / \mathrm{L}$ of acid volatile sulfide (He et al., 2008). Shen and Wilson (2007) attributed as much as one-half of the
Iron sulfides formed by biological processes have been found to be more reactive than naturally occurring species, potentially due to greater surface area. 


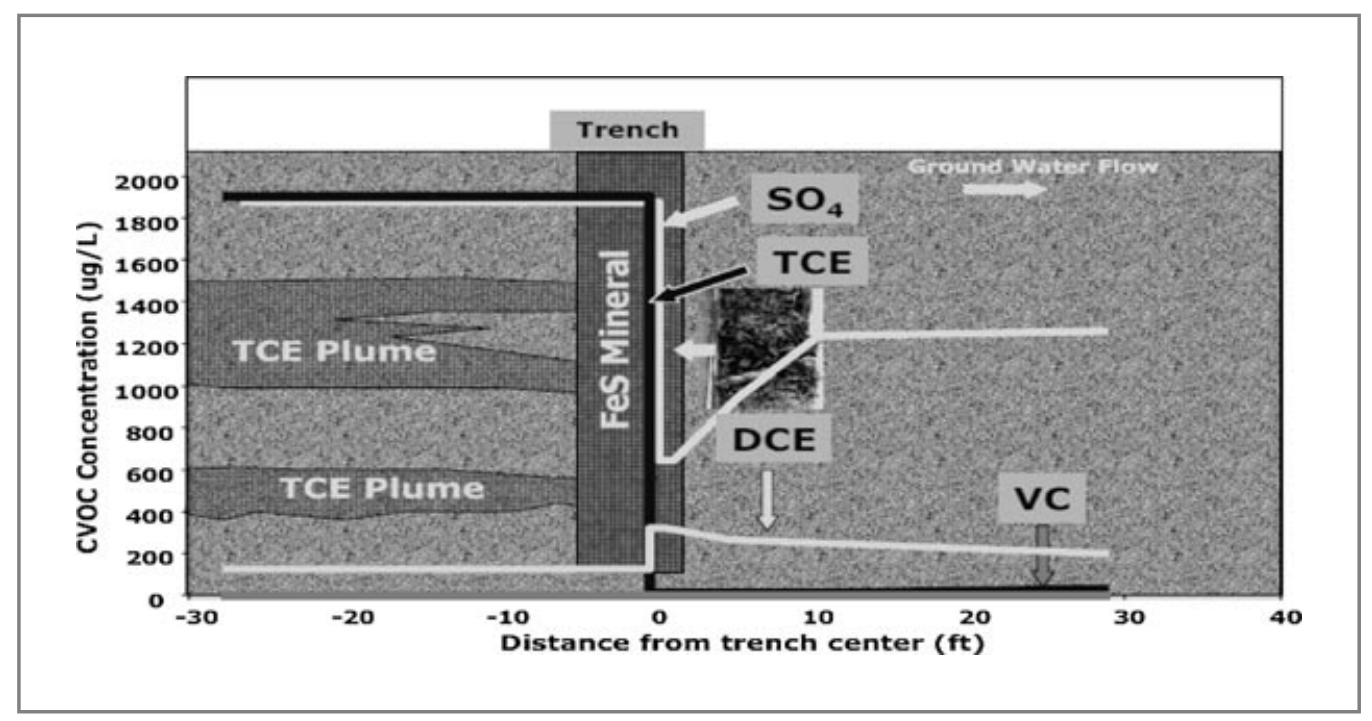

Exhibit 4. Performance of a BiRD trench using biogenic iron sulfides

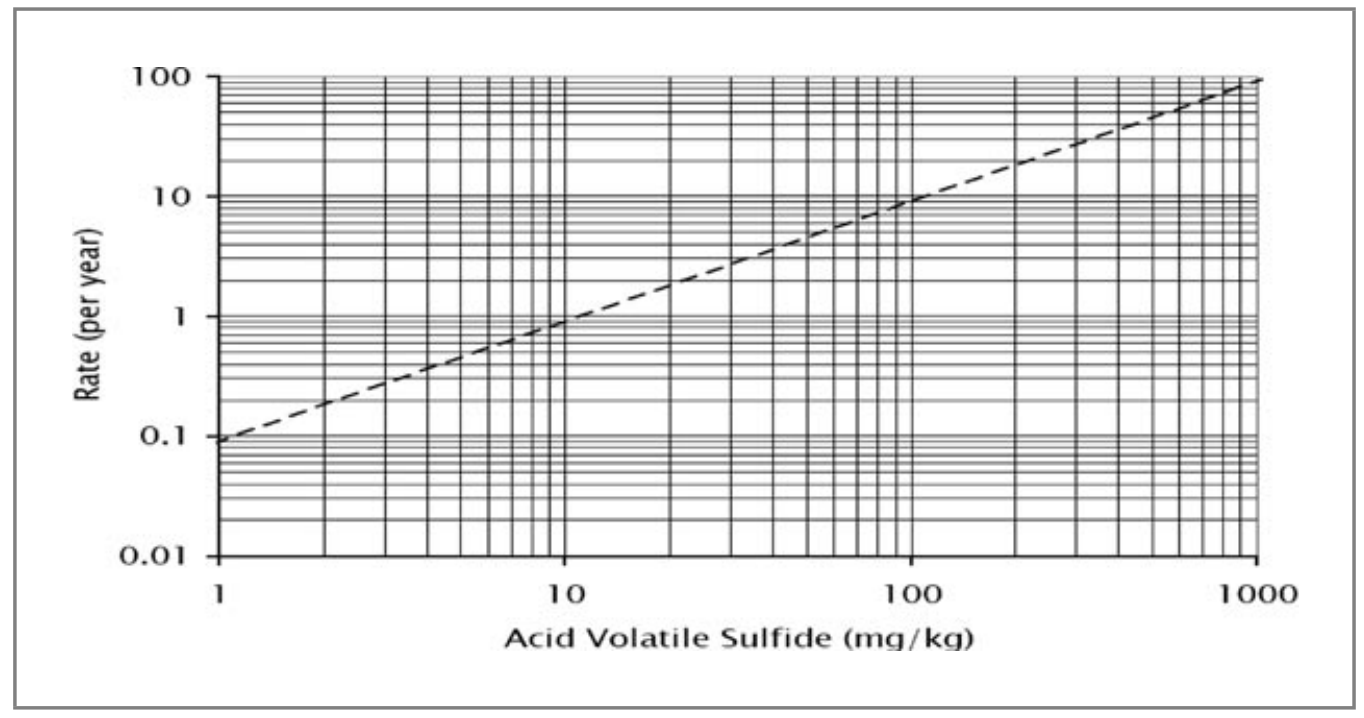

Exhibit 5. Rate TCE removal on biogenic FeS

TCE removal to abiotic reactions with iron monosulfides, and the remainder to biological degradation. The content of iron monosulfides in geological material can be estimated from a determination of acid volatile sulfide (AVS). Analyses of AVS are simple, affordable, and commercially available.

Exhibit 5 compares the pseudo first-order rate constant for removal of TCE that can be expected for reaction of TCE in typical aquifer sediment containing iron monosulfides. The rate constants predicted from Exhibit 5 represent an upper boundary on rates that might be expected in field-scale systems. The exhibit can be used to estimate the potential for TCE removal through abiotic reaction with iron monosulfides.

Groundwater chemistry can sharply influence the formation of minerals and the extent of contaminant transformation that will be mediated by ISCR. Groundwater under 
relatively neutral $\mathrm{pH}$ with little dissolved $\mathrm{O}_{2}$ and $\mathrm{NO}_{3}^{-1}$ and adequate supplies of biodegradable organic carbon, ferrous iron, and reduced/reducible sulfur compounds is likely to support formation of iron monosulfides, which are among the most reactive minerals from an ISCR perspective. In contrast, groundwater, which has the same $\mathrm{pH}$, $\mathrm{O}_{2}, \mathrm{NO}_{3}^{-1}$, and supply of biodegradable organic carbon but lacks reduced/reducible sulfur compounds, is more likely to support formation of magnetite, a somewhat less reactive iron mineral (Lee \& Batchelor, 2002). Thus, the type of reactive minerals formed can influence the rate and extent of CVOC degradation, while the groundwater chemistry influences the type of mineral formed.

\section{SYNERGISTIC INTERACTIONS}

The second type of biotic-abiotic interaction is synergistic reactions in which biological processes are used to improve the performance of abiotic reactions. In synergistic interactions, the biological reactions are coupled to the abiotic reactions.

\section{Synergistic Combinations}

One example of such synergy is $\mathrm{EHC}^{\circledR}$, a commercially available ISCR reagent that combines controlled-release carbon plus ZVI particles (www.adventusgroup.com). With $\mathrm{EHC}^{\circledR}$, a number of physical, chemical, and microbiological processes combine to create a very strong reducing environment (e.g., Eh $<-550 \mathrm{mV}$ ) that stimulates rapid and complete dechlorination of organic solvents and other recalcitrant compounds (Seech et al., 1995). At this low of an Eh, many chlorinated solvents are thermodynamically unstable (Dolfing et al., 2008). Chlorinated solvents readily degrade via pathways more typical of physical destruction processes, which yield minimum production and no accumulation of typical biodegradation intermediates, such as DCE for TCE.

The carbon component of $\mathrm{EHC}^{\circledR}$ has several functions. First is biological reduction/consumption of oxygen and nitrate, which can interfere with or inhibit abiotic reactions. Next is buffering capacity. Fermentation of the organic component liberates organic acids, which counter the production of hydroxyl ions resulting from the ZVI corrosion process, leading to more reactive ZVI surfaces. Third is metal precipitation. In the presence of sulfate, $\mathrm{EHC}^{\circledR}$ can cause sulfate reduction, which leads to precipitation of heavy metals. The primary mechanism of removal is hypothesized to consist of the precipitation and coprecipitation of metals with iron/sulfur compounds. For example, arsenic precipitation is associated with the reduction of sulfate to sulfide and formation of stable arsenopyrite (FeAsS; Craw et al., 2003), thereby transferring it from the aqueous phase to the solid phase.

An example of these synergistic effects is also seen in the degradation of 1,2-dichloroethane (1,2-DCA). Typically, treatment of 1,2-DCA with ZVI only, or sources of carbon only, yields limited and, at best, incomplete degradation. As discussed later, $\mathrm{EHC}^{\circledR}$ achieved rapid and complete mineralization of 1,2-DCA without accumulating catabolites.

A bench-scale column study was conducted on groundwater from a site impacted with 1,2-DCA. The total volatile organic compound (VOC) concentration of the site
Groundwater chemistry can sharply influence the formation of minerals and the extent of contaminant transformation that will be mediated by ISCR. 
Results show that the $\mathrm{EHC}^{\circledR}$-amended soil columns reduced 1,2-DCA from an initial concentration of $24 \mathrm{mg} / \mathrm{L}$ by 95 percent with a 100 percent molar conversion to chloroethane (CA) in 35 days. groundwater was $337 \mathrm{mg} / \mathrm{L}$, and the 1,2-DCA concentration was $329 \mathrm{mg} / \mathrm{L}$. The study setup used a column followed by two soil microcosms. In the reactive setup, the column and first downstream soil microcosm were filled with site soil supplemented with 1 percent $\mathrm{EHC}^{\circledR}$ (by mass). The second soil microcosm was filled with site soil alone. This experimental setup was designed to mimic an injection of $\mathrm{EHC}^{\circledR}$ into the subsurface at the site. The second soil microcosm, containing only site soil, was added to monitor any further degradation of VOCs that may occur downgradient of the reactive zone. A control system was also set up as described earlier, except no $\mathrm{EHC}^{\circledR}$ was added to the column and soil microcosms. VOC and chloride concentrations were monitored in the influent and effluents over time.

VOC sampling on day 98 revealed a 99+ percent reduction in 1,2-DCA from $329 \mathrm{mg} / \mathrm{L}$ in the feed to $83 \mathrm{mg} / \mathrm{L}$ and $0.041 \mathrm{mg} / \mathrm{L}$ in the column and first soil microcosm effluents, respectively. The 1,2-DCA concentration was further reduced to $0.019 \mathrm{mg} / \mathrm{L}$ in the second soil microcosm. Chloroethane, a potential breakdown product of 1,2-DCA, was not detected in the effluents. The 1,2-DCA concentration in the final effluent of the control (no $\mathrm{EHC}^{\circledR}$ present) was $221 \mathrm{mg} / \mathrm{L}$, which corresponded to a 33 percent removal of 1,2-DCA, most likely due to native dechlorinators present in the site soil and groundwater. The chloride mass balance confirmed dechlorination of the VOCs in the $\mathrm{EHC}^{\circledR}$ columns (99 percent chloride recovery, based on the percent removal of 1,2-DCA), while the control system showed little production of chloride (less than 15 percent chloride).

A second bench-scale study compared the treatment of 1,2-DCA in ZVI or $\mathrm{EHC}^{\circledR}$-amended soil columns over a period of 223 days. Results show that the EHC $^{\circledR}$-amended soil columns reduced 1,2-DCA from an initial concentration of $24 \mathrm{mg} / \mathrm{L}$ by 95 percent with a 100 percent molar conversion to chloroethane (CA) in 35 days (Exhibit 6). The molar ratio of CA was reduced to 42 percent after 64 days, and after 223 days there were no detections of 1,2-DCA or CA in the column effluent. In comparison, the soil column amended with ZVI only showed 26 percent, 20 percent, and 4 percent reductions in 1,2-DCA on days 35, 65, and 223, respectively. This study showed that 1,2-DCA is more effectively treated under the synergistic ISCR conditions created with $\mathrm{EHC}^{\circledR}$ than with ZVI alone.

A second type of synergy between biotic and abiotic reactions is the role of reduced iron. Bacteria readily reduce iron in the presence of degradable carbon substrates releasing soluble ferrous iron. Ferrous iron can then bind to the surface of iron minerals creating reactive sites.

Lee and Batchelor (2002) evaluated the ability of pure magnetite to dechlorinate PCE, TCE, cis-DCE, and VC in a laboratory study. The first-order rate constant at reactive mineral sites varied from 0.185 to 1.71 per day. They found that the addition of $\mathrm{Fe}^{+2}$ to a magnetite suspension increased the rate of dechlorination by a factor of nearly ten. Other iron minerals capable of dechlorination include green rust (Fe(II)Fe(III)hydroxide), iron sulfides, and others. The chemisorption of ferrous iron onto the surfaces of such minerals was generally found to increase the reactivity of the mineral (AFCEE, 2008).

Scherer and Larese-Casanova (2007) studied the effect of adding $\mathrm{Fe}^{+2}$ on the reactivity of magnetite in the reduction of $\mathrm{RDX}$ (Exhibit 7). Neither $\mathrm{Fe}^{+2}$ nor magnetite alone showed significant reduction of RDX over 200 hours. The addition of soluble Fe ${ }^{+2}$ to magnetite, however, increased the rate of RDX reduction by greater than 20 -fold. 


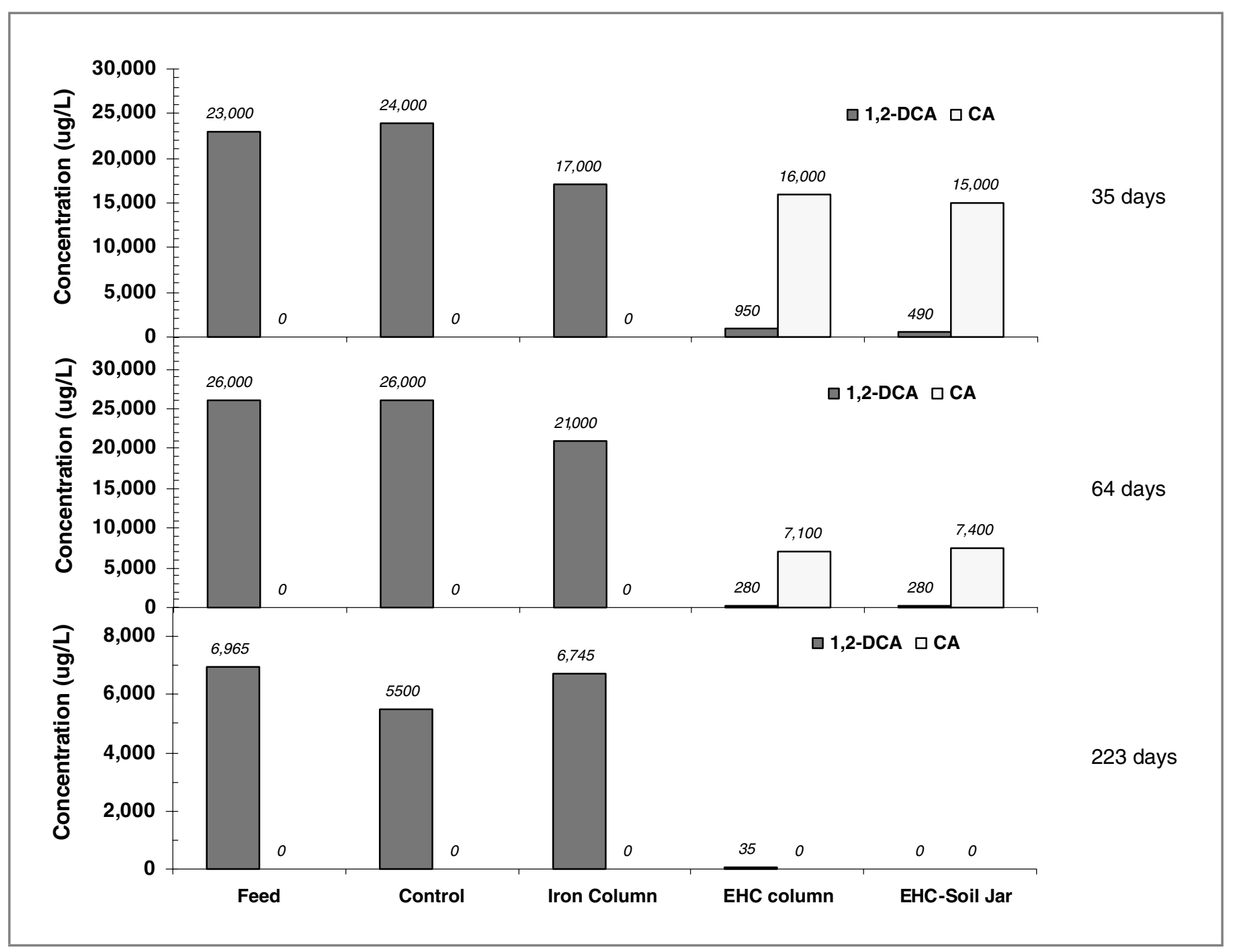

Exhibit 6. Influence of EHC and ZVI on treatment of 1,2-DCA

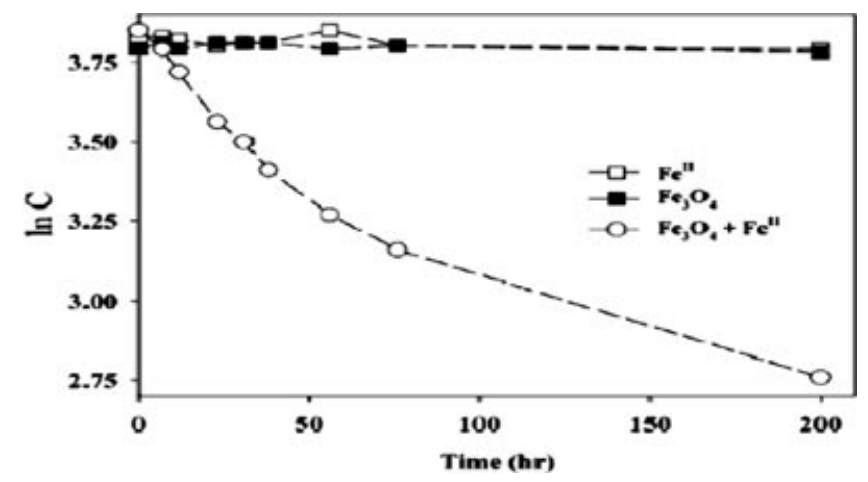

Exhibit 7. First-order plot of $47 \mu \mathrm{M}$ of RDX reduction in the presence of $1.5 \mathrm{mM}$ of $\mathrm{Fe}^{+2}$ and a magnetite suspension $\left(44 \mathrm{~m}^{2} / \mathrm{L}\right)$ at $\mathrm{pH}$ of 7.0 
In the presence of reduced minerals or minerals with mixed iron valences, the biological production of soluble ferrous iron can improve the reducing capacity and kinetics of the minerals.

An implication of this type of synergy is the coupling of biodegradation to abiotic reduction. Naturally occurring biological processes could result in abiotic attenuation. If soluble iron is produced biologically and if there is an iron-rich mineralogy present, a reducing mineral could be created as a result of the biological activity creating an under-layer of abiotic activity. This mineral could be collocated with the biologically active zone or it could be created downgradient.

\section{CONCLUSION}

Biological and abiotic dechlorination processes have previously been viewed as separate pathways and not interrelated. This is in part because abiotic processes are surface-catalyzed processes relying on minerals or on metals like ZVI while biological processes were viewed as aqueous-phase reactions relying on microorganisms.

This viewpoint is changing. Biological processes and abiotic processes have a strong interrelationship. The interaction can be causative. Biological processes can produce reduced-iron minerals, such as pyrite, magnetite, or green rust. Sulfate reduction and iron reduction are two of the key metabolic pathways. The biological production of iron sulfides is the basis of AFCEE's BiRD technology.

The interaction also can be synergistic. Biological processes can enhance the reactivity of abiotic materials. EHC ${ }^{\circledR}$ intentionally uses this synergy by combining ZVI with a degradable carbon substrate. The production of dissolved iron II can create highly reactive sites on iron minerals through chemisorption.

Further understanding of the interaction between biotic and abiotic reactions can lead to the development of improved remedial methods. It has implications for both aggressive remediation as well as natural attenuation.

Effective site management requires a holistic understanding of contaminant attenuation, regardless of the form it takes. Abiotic mechanisms are effective at degrading contaminants, and some abiotic remedial technologies have been shown to be viable at contaminated sites; others will likely emerge that combine biotic and abiotic processes. Increasing our understanding of these processes will improve management of contaminated sites and, in doing so, help ensure contaminated sites are managed to be protective of human health and the environment.

\section{REFERENCES}

Air Force Center for Engineering and the Environment (AFCEE). (2008). Workshop on in situ biogeochemical transformation of chlorinated solvents. Port Hueneme, CA: Naval Facilities Engineering Service Center.

Arnold, W. A., \& Roberts, A. J. (2000). Pathways and kinetics of chlorinated ethylene and chlorinated acetylene reaction with Fe(0) particles. Environmental Science \& Technology, 34, 1794-1805.

Brown, R. A., Hines, R., Cho, J., \& Leahy, M. (2006). Abiotic and biotic pathways in chlorinated solvent natural attenuation. Presented at the Fifth International Conference on Remediation of Chlorinated and Recalcitrant Compounds. Monterey, CA. 
Chaudhuri, S. K., Lack, J. G., \& Coates, J. D. (2001). Biogenic magnetite formation through anaerobic biooxidation of Fe(II). Applied and Environmental Microbiology, 67, 2844-2848.

Craw, D., Falconer, D., \& Youngson, J. H. (2003). Environmental arsenopyrite stability and dissolution: Theory, experiment, and field observations. Chemical Geology, 199, 1-2, 71-82.

Dolfing, J., van Eekert, M., Seech, A., Vogan, J., \& Mueller, J. (2008). In situ chemical reduction (ISCR) technologies-Significance of low Eh reactions. International Journal of Soil \& Sediment Contamination, $17(1), 63-74$.

Ferrey, M. L., Wilkin, R. T., Ford, R. G., \& Wilson, J. T. (2004). Nonbiological removal of cis-dichloroethylene and 1,1-dichloroethylene in aquifer sediment containing magnetite. Environmental Science \& Technology, 38, 1746-1752.

He, Y. T., Wilson, J. T., \& Wilkin, R. T. (2008). Transformation of reactive iron minerals in a permeable reactive barrier (biowall) used to treat TCE in groundwater. Environmental Science \& Technology, 42, 6690-6696.

Kennedy, L. G., Everett, J. W., Becvar, E., \& DeFeo, D. (2006). Field scale demonstration of induced biogeochemical reductive dechlorination at Dover Air Force Base, Dover Delaware. Journal of Contaminant Hydrology, 88, 119-136.

Lee, W., \& Batchelor, B. (2002). Abiotic reductive dechlorination of chlorinated ethylenes by iron-bearing soil minerals. 1. Pyrite and magnetite. Environmental Science \& Technology, 36, 5147-5154.

Moore, R. C. (2003). In situ formation of magnetite reactive barriers in soil for waste stabilization. U.S. Patent $6,527,691$.

Scherer, M. M., \& Larese-Casanova, P. (2007). Fe(II) sorption on hematite: New insights based on spectroscopic measurements. Environmental Science \& Technology, 41(2), 471-477.

Seech, A. G., Cairns, J. E., \& Marvan, I. J. (1995). Method for dehalogenation and degradation of halogenated organic contaminants. U.S. Patent No. 5,411,664.

Shen, H., \& Wilson, J. T. (2007). Trichloroethylene removal from groundwater in flow-through columns simulating a permeable reactive barrier constructed with plant mulch. Environmental Science \& Technology, 41, 4077-4083.

Szecsody, J. E., Fruchter, J. S., Williams, M. D., Vermeul, V. R., \& Sklarew, D. S. (2004). In situ chemical reduction of aquifer sediments: Enhancement of reactive iron phases and TCE dechlorination. Environmental Science \& Technology, 38, 4656-4663.

Wilson, J. T. (2003). Abiotic reactions may be the most important mechanism in natural attenuation of chlorinated solvents. Presented at the AFCEE Technology Transfer Workshop, Brooks AFB, San Antonio, TX.

Richard A. Brown, PhD, is a technical director for ERM, Inc. based in Ewing, New Jersey. His area of focus is the development and implementation of technologies for the investigation and remediation of hazardous waste sites. Dr. Brown received his BA in chemistry from Harvard University and his MS and PhD in inorganic chemistry from Cornell University.

James G. Mueller, $\mathrm{PhD}$, is president and director of remedial strategies at Adventus Americas Inc., in Corona Del Mar, California. Adventus focuses on the application of environmental biotechnologies to remediate 
impacted sites. Dr. Mueller received his BS and MS degrees in soil microbiology and biochemistry from Southern Illinois University and his PhD at Clemson University. He completed postdoctoral training at the US EPA's Environmental Biotechnology laboratory in Gulf Breeze, Florida.

Alan G. Seech, PhD, is chief executive officer and director of technology for Adventus Americas Inc., in Corona Del Mar, California. His research focuses on reductive processes for removal of pesticides, CVOCs, organic explosive compounds, and heavy metals from soil and groundwater. Dr. Seech has a BS from Ontario Agricultural College. He received his M.Sc. in Soil Chemistry and PhD in environmental microbiology from the University of Guelph.

James K. Henderson, $\mathrm{PhD}$, is a project director for the DuPont Corporate Remediation Group based in Charlotte, North Carolina. He is responsible for environmental investigation and remediation of DuPont industrial plants and properties in Central and South America. Dr. Henderson received a BA from Dickinson College, an MS in environmental studies from California State University, Fullerton, and a PhD in environmental science and engineering from Clemson University.

John T. Wilson, PhD, is a research microbiologist with the US EPA National Risk Management Research Laboratory, in Ada, Oklahoma. He leads research dealing with biological and nonbiological processes that destroy contaminants in groundwater. The research is applied to active remedial technology and to monitored natural attenuation. Dr. Wilson has a BS in biology from Baylor University, an MA in microbiology from the University of California at Berkeley, and a PhD in microbiology from Cornell University. 